\title{
Risk Assessment of People Trapped in Earthquakes Based on Km Grid: A Case Study in Zhaotong City, Yunnan, China
}

\author{
Benyong Wei ${ }^{1}$, Xiang Dong ${ }^{2}$, Yuling $\mathrm{Ma}^{3}$ \\ ${ }^{1}$ Institute of Geology, China Earthquake Administration, Beijing 100029, China \\ ${ }^{2}$ Shandong Earthquake Agency, Jinan 250014, China \\ ${ }^{3}$ National disaster reduction center of the Ministry of civil affairs, Beijing 100124, China

\section{基于公里格网的地震人员埋压风险评估一以云 南昭通市为例} \\ 魏本勇 ${ }^{1}$, 董翔 ${ }^{2}$, 马玉玲 ${ }^{3}$ \\ ${ }^{1}$ 中国地震局地质研究所, 北京 100029 , 中国 \\ ${ }^{2}$ 山东省地震局, 济南 250014, 中国 \\ ${ }^{3}$ 民政部国家减灾中心, 北京 100124 , 中国
}

\begin{abstract}
Risk assessment of the trapped personnel location is the important basis for earthquake disaster risk preparation and emergency search and rescue in an earthquake. Using a constructed assessment model, we assessed the risk of people trapped in the collapsed buildings caused by an earthquake in Zhaotong city, Yunnan province, based on $\mathrm{km}$ grid data. Results showed that, the highest risk areas of trapped personnel distribution were mainly located in Zhaoyang district, Zhenxiong county and Weixin county. The higher the occupancy population density and the area of collapsed buildings are, the higher the risk level of people trapped. The grid-based assessment of people trapped in earthquakes, can meet the requirements of key search and rescue zone identification and rescue forces allocation in the early stage of earthquake emergency. In future, as the abundant and improvement of basic data, it is possible to
\end{abstract}

provide more information and suggestions for earthquake disaster risk preparation and emergency search and rescue by using gridbased risk assessment of trapped people in earthquakes.

Keywords: earthquake disaster; casualty; $\mathrm{Km}$ grid; risk assessment; Yunnan

\section{摘要}

地震灾区人员埋压风险的评估, 可以 为政府针对性的防震减灾救援防范提供重 要的科学依据。本文基于公里格网数据, 通过考虑建筑物倒塌率、在室率和自救互 救率, 构建了地震埋压人员分布评估模型, 并对云南省昭通市的地震人员埋压风险进 行了评估。结果表明, 昭通市总体的区域 地震人员埋压高风险区主要位于昭阳区、 镇雄县和威信县。全市人员埋压的高风险 点域, 是地震发生时在室人口最为密集和 建筑物倒塌面积最高的区域, 也是昭通市 未来地震预防与减灾, 及震后地震应急救 援的重点区域。未来, 随着基础数据的丰 
富与完备, 基于公里格网的地震埋压人员 风险评估, 可以为地震预防与应急救援工 作提供更加准确和有效的参考。

关键词：地震灾害; 人员伤亡; 公里格网; 风险评估; 云南

\section{1. 引言}

中国是一个地震灾害频发的国家。快 速挽救生命, 最大限度地减少人员伤亡, 是震后应急救援工作的首要之重。加强对 地震灾区人员埋压风险的评估研究, 不仅 可以为政府进行震后应急救援力量和资源 的合理调配提供重要的依据, 也可以最大 限度地提高被埋压者的生存概率, 减少地 震人员伤亡。

目前国内外关于地震灾害人员损失风 险的评估研究, 主要集中于人员伤亡损失 评估方面 ${ }^{[1-5]}$ 。近几年, 随着地震应急工作 的需要, 也有一些研究开始关注地震灾害 中的人员埋压风险 ${ }^{[6-7]}$ 。最近, 通过对地震 人员埋压主要影响因素的梳理分析, 我们 发现, 建筑物倒塌和人员在室, 是造成地 震中建筑倒塌人员埋压的两个先决条件 ${ }^{[8]}$ 。 通过综合考虑地震危险性、建筑物易损性、 人口密度、在室率及自救互救等多个方面, 我们构建了一个针对建筑物倒塌引起的地 震埋压人员分布评估模型 ${ }^{[9]}$ 。虽然目前已有 一些关于地震灾害中人员埋压风险的研究, 但仍需大量实证研究来完善其理论与应用 方法体系。本文在前期研究的基础上, 基 于公里格网数据, 对云南省昭通市设定地 震影响下的人员埋压风险进行了评估, 以 期为当地地震风险预防及应急救援策略的 制定提供实证参考。

\section{2. 研究区概况}

云南省昭通市位于云南省东北部, 地 势西南高、东北低, 属典型的山地构造地 形, 山高谷深。市内平均海拔 $1685 \mathrm{~m}$, 最 高海拔 $4040 \mathrm{~m}$, 最低海拔 267m。2010 年末 总人口约 521.3 万, 其中有苗、彝、回等 23 个少数民族 54.2 万人。全市将近 $80 \%$ 的 乡村居民点属于山区坡地聚落。由于地处 乌蒙山贫困片区, 全市 11 个县/区中有 10 个县区为国家重点扶贫县。
昭通是云南省地震灾害频发、灾害损失最 为严重的区域之一。根据统计, 20 世纪以 来, 昭通市共发生破坏性地震 19 次, 其中 Ms 5.5 级及以上地震 9 次, Ms 6.5 级及以 上地震 3 次, 最大震级地震为 1974 年 5 月 11 日发生在昭通大关北的 Ms 7.1 级地震。 在 1900-2012 年的 100 多年间, 昭通地区 发生的地震分别占云南地区 Ms 5.0-5.9 级 地震的 $8.81 \%$, Ms 6.0-6.9 级地震的 $3.64 \%$, Ms 7.0 级以上地震的 $9.09 \%$ 。

\section{3. 方法与数据}

\section{1 数据资料}

前期研究表明, 公里格网尺度的地震 压埋人员分布评估结果, 更有助于对比区 域差异, 判定重点搜救区域, 从而为地震 灾害风险防范与震后应急救援提供更精确 地指导。因此, 本文选择公里格网 ( $1 \mathrm{~km} \times$ $1 \mathrm{~km}$ ) 尺度作为基本评估单元。基础数据资 料包括公里格网的昭通市人口分布数据和 不同结构的建筑物分布数据, 其中人口数 据来自 2010 年六普人口普查数据, 建筑物 数据是来自依据 2010 年住房普查及现场抽 样调查分析的内部研究成果。

\section{2 地震影响情景的确定}

地震危险性程度是进行地震灾害风险 评估的基础。通常用地震烈度、震级、震 源深度、地震动加速度等参数来表征地震 发生时的影响范围和破坏程度。由于地震 烈度是目前对建筑物进行震前抗震设计与 震后破坏程度调查的主要依据, 因而本文 选择烈度来表征地震影响程度。另外, 根 据前期研究 ${ }^{[9]}$, 本文将主要评估地震烈度IX 度和VIII度区影响下的昭通市地震埋压人员 分布风险。

(1) 建筑物倒塌率的确定

为了准确地反映云南地区的建筑物震 害破坏特点, 我们采用周光全等 ${ }^{[10]}$ 通过统 计分析 1992-2003 年 50 次历史地震不同 烈度区的破坏比、损失比和震害指数, 而 给出的云南地区房屋建筑的震害矩阵。同 时, 参考以往研究, 我们将震害等级分类 中的毁坏率作为倒塌率分析 (表 1)。 
表 1. 云南地区不同结构房屋建筑物倒塌率 (\%)

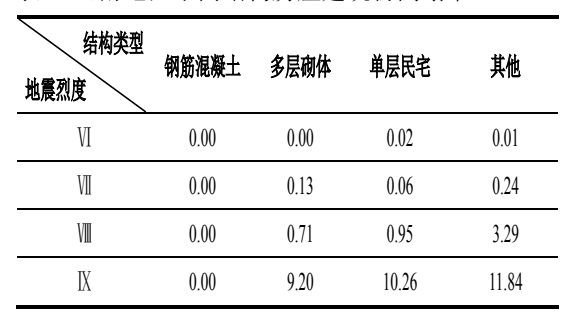

(2) 人员在室率的确定

在一天当中的不同时间段内, 建筑物 内的人员在室率存在明显差异, 而且这种 差异受工作日和节假日的影响也表现出不 同。因而，地震发生时间对于灾区人员损 失程度有着重要的影响。本文假定地震发 生在节假日的 16 时左右, 参考前期研究 ${ }^{[6,9}$, ${ }^{11]}$, 可以得到地震发生时当地居民的平均在 室率约为 0.75 。

（3）灾民自救互救率的确定

灾民自救互救程度是影响震害中人员 损失程度的重要因素。根据对以往震例的 统计显示, 震后通过自救互救而逃生的人 员比例达到 85\%-90\%左右 ${ }^{[12-14]}$ 。考虑到区 域差异性, 本文保守性的将自救互救率设 定在 $85 \%$ 的水平。

\section{3 评估模型}

在前期研究中, 我们基于关键影响因 素分析, 给出了一种评估地震埋压人员分 布的方法和模型。该模型不仅考虑了不同 建筑物结构在特定地震烈度下的倒塌率, 还考虑了地震发生时毁坏建筑物内的在室 率以及灾民的自救互救率。对 2014 年云南 鲁甸 6.5 级地震的评估验证表明, 模型评 估得到的鲁甸地震人员埋压分布与实际调 查结果基本一致; 模型评估结果能够满足 地震初期应急管理部门对于地震应急救援 需求和资源调配的需要 ${ }^{[9]}$ 。因而, 本文将以 前期构建的模型方法为基础, 对研究区内 的地震人员埋压风险进行评估。其具体评 估模型如下:

$$
B_{\text {peop }}=(1-\delta) \times R_{d} \times P(t) \times \sum \sum B_{s} \times L_{s}(I)
$$

其中, Bpeop 为评估单元内的埋压人数; $\mathrm{Rd}$ 为评估单元内单位建筑面积的平均人口
密度; $P(t)$ 为地震发生 $t$ 时刻, 评估单元 内倒塌建筑物的平均人员在室率; $B s$ 为评 估单元内 $\mathrm{s}$ 类建筑物的总面积; Ls (I) 表示 在烈度 I 下评估单元内 $\mathrm{s}$ 类建筑物的倒塌 率; $\delta$ 代表地震后的自救互救率。

\section{4. 结果分析}

\section{1 建筑物倒塌风险分布}

图 1 展示了地震情景下云南昭通市房 屋建筑物的倒塌风险分布。从图中可以看 出, 在地震烈度 VIII度影响下, 昭通市总体 的建筑物倒塌风险较低, 平均每平方公里 的建筑物倒塌面积在 $500 \mathrm{~m}^{2}$ 以下。相对倒 塌风险较高的区域主要集中于昭阳区风凰 街道中西部、旧圃镇, 镇雄县泼机镇、中 屯乡、塘房镇, 鲁甸县文屏镇北部和茨院 乡南部的交接地区, 总体上建筑物的抗倒 塌水平较高 (图 1(a))。然而, 当地震烈度 达到IX度区影响时, 昭通市总体的建筑物 倒塌风险显著升高 (图 1(b)), 除少数乡镇 外, 大部分乡镇平均每平方公里的建筑物 倒塌面积都在 $1000 \mathrm{~m}^{2}$ 以上。尤其昭阳区中 南的风凰街道、旧戋镇、永丰镇、守望乡, 镇雄县东南的泼机镇、中屯乡、乌峰镇、 塘房镇, 鲁甸县东北的文屏镇、茨院乡、 桃源乡等, 是建筑物倒塌风险最高的地区。 从中也可以看出, 昭通市昭阳区中南部、 鲁甸县东北部、镇雄县及威信县是建筑物 倒塌风险相对较高的区域, 尤其是在面临 IX 度及以上烈度水平的地震冲击时更容易 造成大范围的房屋倒塌或毁坏。

\section{2 震时在室人口分布}

图 2 展示了设定地震发生时昭通市的 在室人口分布。从中可以看出, 昭通市各 地区的人口分布并不均匀, 其中, 昭阳区 中南的凤凰街道、旧戋镇、永丰镇、守望 乡, 镇雄县东南的泼机镇、中屯乡、乌峰 镇、塘房镇, 鲁甸县东北的文屏镇、茨院 乡、桃源乡, 彝良县角奎镇和威信县扎西 镇是单位在室人口密度相对最高的地区。 这也意味着如果这些地区发生建筑物倒塌, 其埋压的在室人口也将最多。 


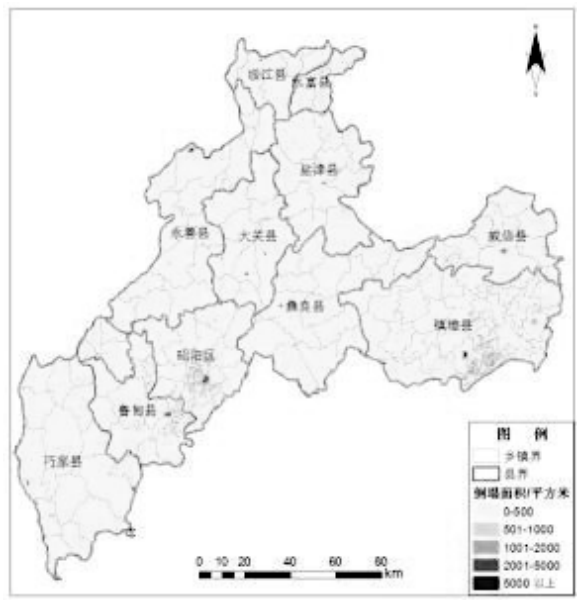

(a) VIII度区覆盖

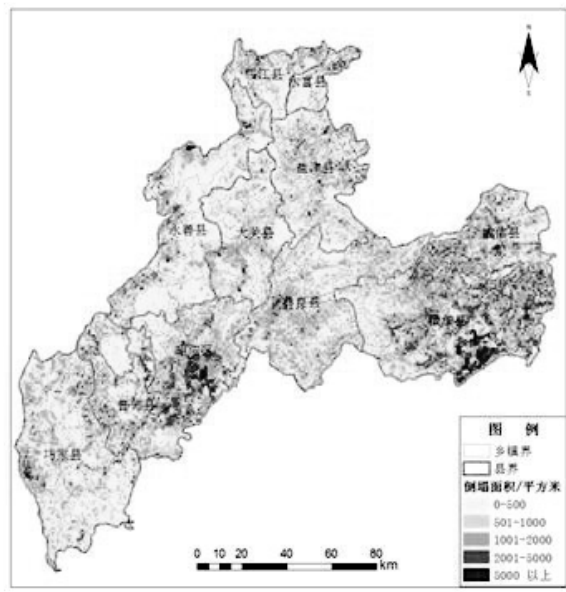

(b) IX度区覆盖

图 1 云南昭通市建筑物倒塌风险分布

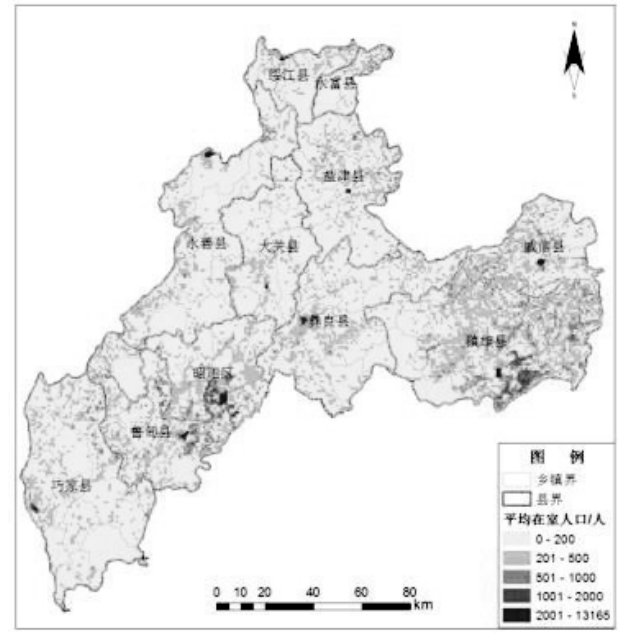

图 2 设定地震发生时昭通市在室人口分布 


\section{a}

\section{3 地震人员埋压风险}

图 3 展示了在设定的地震影响区下, 云南昭通市由于房屋建筑物倒塌而引起的 人员埋压风险分布情况。在地震烈度 VIII度 影响下 (图 3(a)), 首先从区县级层面看, 昭阳区和镇雄县是人员埋压风险相对较高 的地区; 而从乡镇角度看, 昭阳区凤凰街 道西中部、镇雄县乌峰镇中部、彝良县角 奎镇北西部、鲁甸县文屏镇北部地区、威 信县扎西镇中北部、永善县溪洛渡镇北西 部、绥江县中城镇北中部、盐津县盐井镇 中东部, 是全市人员埋压的高风险点。在 烈度IX度区影响下 (图 3(b)), 昭通市总体 的区域人员埋压风险与 VIII度影响下的风险
分布是基本一致的, 但是其风险程度显著 高于 VIII度影响下的风险水平。从区县级层 面看, 昭阳区、镇雄县和威信县是地震人 员埋压风险相对最高的区域; 从乡镇角度 看, 昭阳区风凰街道西中部、旧圃镇大部、 守望乡中北部, 镇雄县泼机镇大部、中屯 乡大部、乌峰镇中部、塘房镇南部, 彝良 县角奎镇中西部, 鲁甸县文屏镇西北部、 茨院乡南部、桃源乡西部、龙树乡中部 (南北条带状), 威信县扎西镇中北部, 永 善县溪洛渡镇北西部, 绥江县中城镇北中 部, 巧家县白鹤滩镇西南部, 盐津县盐井 镇中东部等, 是全市人员埋压的高风险点 域, 也是未来地震预防与减灾, 及震后地 震应急救援的重点区域。

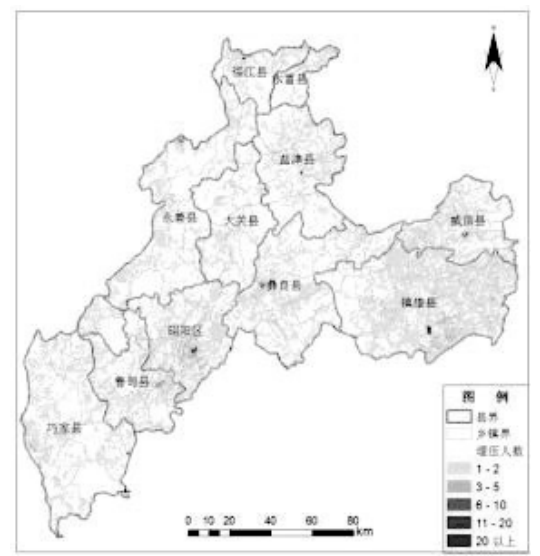

(a) VIII度区覆盖

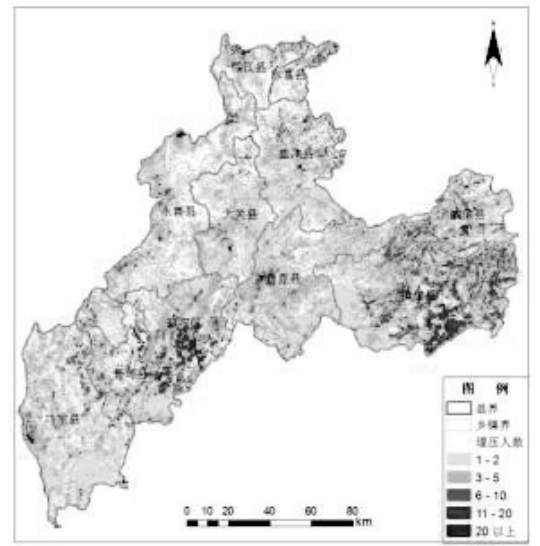

(b) IX度区覆盖

图 3 云南昭通市地震人员埋压风险分布 


\section{5. 结论与讨论}

本文基于公里格网数据, 利用构建的 地震埋压人员风险评估模型, 对云南省昭 通市的地震人员埋压风险进行了评估。结 果表明, 无论是在烈度IX度区, 还是 VIII度 区影响下, 昭通市总体的区域人员埋压风 险分布是基本一致的, 但是烈度 IX度区影 响下的风险程度显著高于VIII度影响下的风 险水平。总体看, 昭阳区、镇雄县和威信 县是地震人员埋压风险相对最高的区域。 从乡镇角度看, 昭阳区凤凰街道西中部、 旧戋镇大部、守望乡中北部, 镇雄县泼机 镇大部、中屯乡大部、乌峰镇中部、塘房 镇南部, 彝良县角奎镇中西部, 鲁甸县文 屏镇西北部、茨院乡南部、桃源乡西部、 龙树乡中部, 威信县扎西镇中北部等, 是 全市人员埋压的高风险点域。通过文中分 析也可以看出, 这些高风险点域也是地震 发生时在室人口最为密集和建筑物倒塌面 积最高的区域。因而, 这些区域也应该是 昭通市未来地震预防与减灾, 及震后地震 应急救援的重点区域。

震后影响建筑物倒塌埋压人员的因素 是多方面的, 且具有一定的不确定性。房 屋倒塌和人员在室是其中两个关键的先决 条件。除此之外, 灾区民众的自救互救能 力、人口流动性等因素也是影响人员实际 埋压程度的重要因素。因此, 严格强调压 埋人员数量的精确性并不现实, 且必要性 也不大。根据前文研究, 人口分布和建筑 物数据的详细与准确程度, 将直接影响着 评估结果的准确性。一般来说, 高空间分 辨率的埋压人员分布评估结果, 将更有利 于震后应急救援力量和资源的目标性调配。 然而, 高空间分辨率的评估, 需要高精度 的基础数据, 而这在实际应用中往往难以 获得。依据我们的研究, 公里格网尺度的 空间分辨率, 已能够满足对地震灾害埋压 人员高风险区的判断需求, 可以为地震灾 害风险防范及震后应急救援提供方向性指 导 ${ }^{[9]}$ 。

最后, 由于基础数据限制, 本研究在 评估过程中也存在一些不足及需要进一步 完善的地方。首先, 地震发生时的地区平
均人员在室率, 与各评估单元实际的人口 流动情况存在一定差别。其次, 地震灾害 中建筑物毁坏率并不完全等同于倒塌率, 尤其对于钢筋混凝土结构的建筑物。另外, 在研究中, 受基础数据的限制, 我们对于 人口和建筑物分布没有区分农村和城市的 差别, 这也将对最终评估结果的准确性产 生影响。未来, 随着基础数据的丰富与完 备, 基于公里格网的地震埋压人员风险评 估, 将可以为区域震害风险防范与震后的 应急救援响应提供更加准确的指导与参考。

\section{致谢}

本研究得到了中国地震局灾情获取与高精 度评估创新团队项目（JH-16-49）、大中城 市地震灾害情景构建重点专项项目 (2016QJGJ13) 和中国地震局地质研究所 基本科研业务专项（IGCEA1406）的共同资 助。

\section{参考文献}

[1] 马玉宏, 谢礼立. 地震人员伤亡估算方 法研究. 地震工程与工程振动, 2000,9 (3): 140-147.

[2] Feng TN, Hong $\mathrm{ZH}$, Wu HJ, et al. Estimation of earthquake casualties using high-resolution remote sensing: a case study of Dujiangyan city in the May 2008 Wenchuan earthquake. Natural Hazards, 2013, 69,1577-1595.

[3] 李媛媛,苏国峰,翁文国等. 地震人员伤 亡评估方法研究. 灾害学, 2014,29(2): 2 23-227.

[4] Park JH, Shin M, Cho GH. A dynamic estimation of casualties from an earthquake based on a time-use survey: applying HAZUS-MH software to Ulsan, Korea. Natural Hazards, 2016, 81,289306.

[5] Corbane C, Hancilar U, Ehrlich D, et al. Pan-European seismic risk assessment: a proof of concept using the earthquake loss estimation routine. Bulletin of Earthquake Engineering, 2017, 15, 10571083. 
[6] 肖东升, 黄丁发, 陈维锋. 基于地震压埋 率的在室率先验性研究. 自然灾害学报, 2009, 18(4):92-97.

[7] 余世舟,张令心,杨明儒.地震埋压人员分 布评估方法初探. 地震工程与工程振动, 2015, 35(2):138-143.

[8] 魏本勇, 聂高众, 苏桂武等. 地震灾害埋 压人员评估的研究进展.灾害学, 2017, 3 2(1): $155-159$.

[9] Wei BY, Nie GZ, Su GW, et al. Risk assessment of people trapped in earthquake based on $\mathrm{km}$ grid: a case study of the 2014 Ludian earthquake, China. Geomatics, Natural Hazards and Risk,2017, 8(2): 1289-1305.

[10] 周光全,谭文红,施伟华等. 云南地区房 屋建筑的震害矩阵. 中国地震, 2007, 23 (2): 115-123.

[11] 田丽莉. 地震灾害人员伤亡影响因素分 析及人员伤亡估算公式. 北京: 首都经 济贸易大学, 2012 .

[12] 修济刚. 防灾减灾教育宣传要注重实效. 城市与减灾, 2004, (4):2-3.

[13] 李平. 从九江地震谈减灾应对. 城市与 减灾, 2006,8(2):9-12.

[14] 曲国胜, 黄建发. 汶川特大地震灾害救 援与我国救援体系建设的思考. 四川行 政学院学报, 2010, (3): 44-46. 